\title{
DIVERGENCE OF PERSPECTIVES ON WOMEN AND HIGHER EDUCATION LEADERSHIP? IN CONVERSATION WITH MEN IN LEADERSHIP
}

\author{
A. L. Moodly \\ Rhodes Business School and Registrar \\ Rhodes University \\ Makhanda/Grahamstown, South Africa \\ https://orcid.org/0000-0003-1636-9972
}

\section{ABSTRACT}

Literature on the challenges and marginalisation of women in higher education and leadership has focused mostly on the voices of women in understanding their experiences. The structural and cultural milieu of the higher education landscape has continuously been put forward as part of a complexity of contributing factors to the challenges. In exploring literature, the author found little that brings men's voices to the discourse. Seeking the voices of men in leadership, was with the understanding that in occupying positions of power and influence, they are strategically positioned and have agency in transforming the structural and cultural milieu. The article focuses on challenges experienced by women on a trajectory to the highest levels of higher education leadership, and engages with men's perspectives on the higher education structural and cultural milieu. The focus is on areas that women have highlighted as barriers within this milieu. The article engages with the conversations with men, including vice chancellors, undertaken as part of a research project, to explore whether there is a common view and understanding of the higher education environment and women's experiences and challenges in this context. Further, whether men in leadership exercise their agency in influencing and challenging the status quo. The article concludes that though there may not necessarily be a divergence in perspectives regarding the milieu and women's experiences therein, this may only be at an empirical/observed level. The deeper, underlying structures and mechanisms that retain the status quo have neither been recognised nor engaged. There is also the danger of complacency and lack of exercising agency in disrupting the status quo, which may contribute to the lack of change. The findings also foreground a wrestling with a myriad of challenges as experienced within the higher education sector, contributing to the lack of prioritising a focus on women towards leadership.

Keywords: Men's perspectives, women and leadership, higher education, deeper structures and mechanisms in higher education, policies in higher education, mentoring and support, old boys' and young boys' network, complacency, agency.

\section{INTRODUCTION}

The purpose of this article is to review men's perspectives on structural challenges within higher 
education that have been identified by women as challenging towards their ascension to senior/executive leadership in the uppermost echelons of University leadership, including that of registrar, deputy vice chancellor and vice chancellor. As reflected in literature, the need for research and a focus on the continuing scarcity of women in leadership positions in various societal domains, despite constituting the majority of the population in most countries, is still pertinent and relevant (Surawicz 2016; Monnapula-Mapesela 2017; Gallagher and Morison 2019; Shinbrot et al. 2019). The patriarchal nature of society continues to perpetuate leadership as male dominated, with slight variations in South African public universities' statistics as reflected in the executive positions. Figure one below reflects the continued poor representation of women as vice-chancellors within these institutions. As is the case internationally, South African women have increasingly accessed higher education and more women graduate than men. Between the years 2012-2017, at both the undergraduate and postgraduate level, women in South African public universities have been in the majority (Council on Higher Education 2019). Despite this, women still occupy positions mostly within middle management, and barriers are still experienced at senior/executive levels (Surawicz 2016; Monnapula-Mapesela 2017; Gallagher and Morison 2019; Shinbrot et al. 2019).

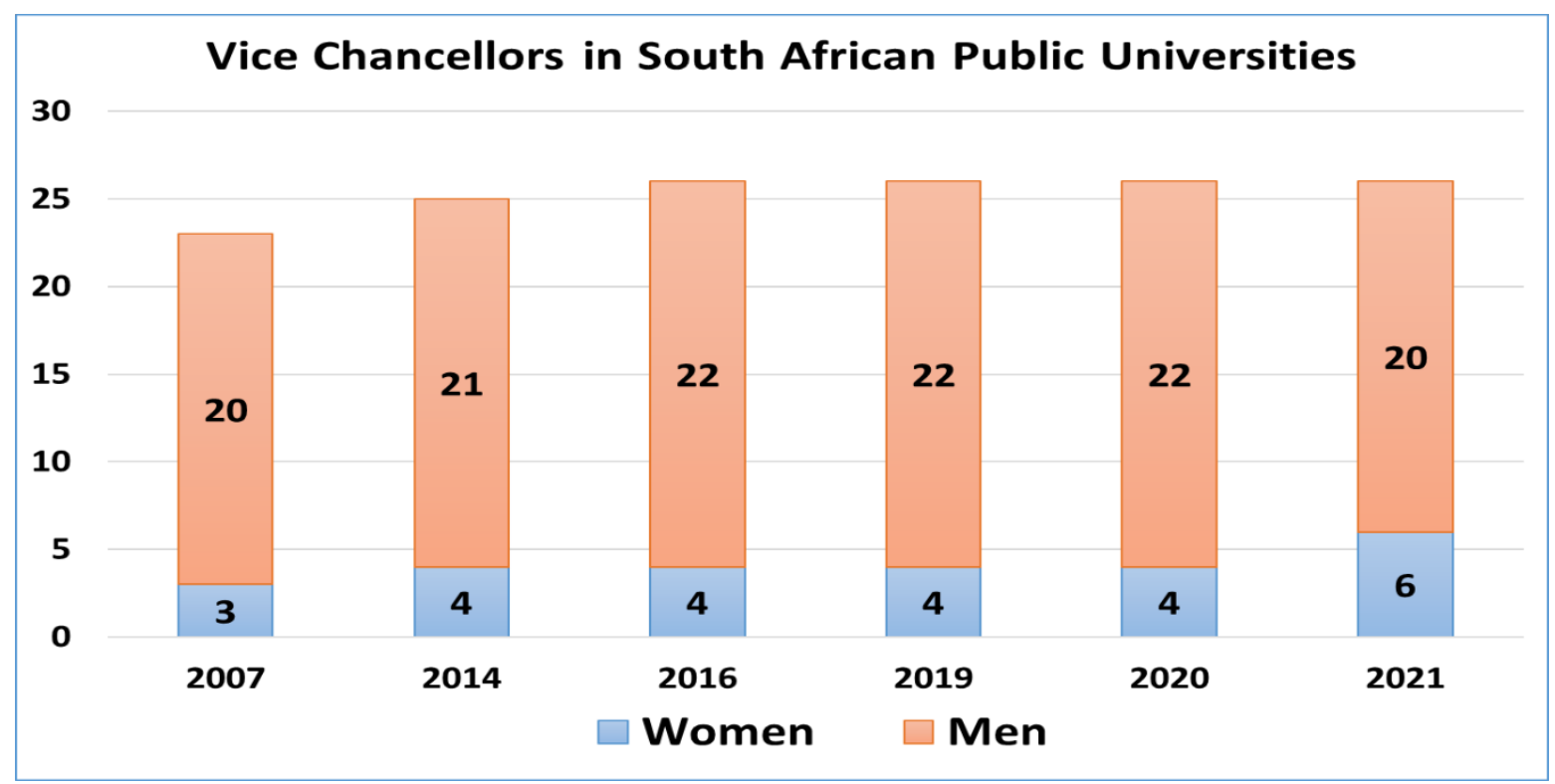

Figure 1: Number of men and women as Vice-Chancellors in South African public universities

Figure one represents the number of women as vice-chancellors over the period 2007 to 2021 . Of the twenty-six vice-chancellors, a desktop review indicates that six were women, a total percentage of 23 per cent. In 2020, 2019 and 2016 the percentage was 15.38 per cent ( 4 of 26). Up until 2020 there was a drop in percentage since a desktop review conducted by Moodly (2015), where in 2014, 16 per cent (4/25) of vice-chancellors were women. In 2007, of the 
twenty-three vice-chancellors, three were women (13\%).

In comparison to a 2015 desktop review of university websites conducted (Moodly 2015), a desktop review of South African universities' websites conducted in 2019 reflected that the number of women in the traditional positions of Deputy Vice-Chancellors (DVC) Research and Academic (also known as Teaching and Learning), as well as the number of women as registrars have increased. The number of women in the position of DVC Research had increased from five (5) in 2013/14 (in twenty-three public universities) to ten (10) in 2019 (in twenty-six public HEIs), and for DVC Academic, it had increased from six (6) in 2013/14 (in twenty-three public HEIs) to eleven (11) (in twenty-six public HEIs), in 2019. In the position of registrar, which was also traditionally a male-occupied space, the number of women was nine (9) at the time of the desktop review in 2019 (in twenty-six public HEIs), in comparison to four (4) in 2013/2014 (in twenty-three HEIs). Of the twenty-six registrars in 2019, only 35 per cent were women. More than 20 years into democracy, we have yet to reach the 50 per cent mark in all positions as highlighted.

\section{ANALYTICAL FRAMEWORK}

The analytical framework is seated within the context of Bhaskar's critical realism (1989), Archer's social realism $(1995 ; 2000)$ and Rawls' theory of social justice (1971. As outlined by Archer (2000, 59-60), Boughey and McKenna (2017, 964) and Monnapula-Mapesela (2017), an understanding of both Bhaskar's conception of reality as layered, and Archer's theory of an "explanatory framework" of a "morphogenetic approach" is important in analysing and interpreting the phenomenon under study. Bhaskar's theory of differentiated levels of reality comprising experienced and observed ("empirical") level, and a deeper level of "actual" events, and the still deeper level of what is "real", where "the structures and mechanisms" interplay reflect that what humans experience at the "empirical" level needs to be analysed and interpreted within the framework of the "actual" and "real" levels (Boughey and McKenna 2017, 964). Archer (2000) argues that though this form of understanding is important, in itself it is not sufficient. She purports that "agency" (the human element) plays a critical role in "morphogenesis ... those processes which tend to elaborate or change a system's form, structure or state" and "morphostatis ... those processes in a complex that preserve (a system) unchanged" (Archer 2000, 60).

The study is further contextualised, as part of a broader research project within the social justice framework of Rawls (1971). Whereas Bhaskar and Archer speak to issues of realism and agency respectively, the context of social inequalities and the need to address such is not necessarily fully encompassed within these theories. Literature reflects that there is not 
necessarily a shared understanding of the term social justice (Chipkin and Meny-Gilbert 2013). Social justice as advocated by Rawls in 1971 (as cited in Ballenger and Austin 2007) and cited in Moodly (2015) and Moodly and Toni (2017c), is an "ethical framework", allowing equal access and fair opportunities to all under conditions which facilitated "equality of fair opportunity". Neier $(2015,47)$ states that "social justice may be defined primarily as distributive justice". In this it considers "social and economic rights" to the extent that it benefits society.

The social justice framework facilitates a compelling argument for the consideration of, at the very least, equal representation of women and men in leadership. This is framed, within the South African milieu, by a majority female population within an oppressive and continual patriarchal system, as reflected in the continued and escalating abuse of girl-children and women. Nkanjeni (2019a) cites Statistics SA statistics on crime, and the World Health Organisation respectively, reflecting that "about 3000 women were murdered (in 2018) - or one every three hours - which is more than five times higher than the global average". Nkanjeni (2019a) further cites Times Live, that "the murder rate for women more than doubled between 2016 and 2016/17" after declining between 2000 and 2015. The tragic focus on the brutal deaths of Uyinene Mrwetyana, Leighandre Jegels, Jesse Hesse, Janika Mall and Meghan Cremer, to name but a few as highlighted in social and mainstream media in South Africa in 2019 (Nkanjeni 2019b; Bonorchis 2019; Carolus 2019), put names and faces to the statistics. The national outcry and marches as reflected at public universities and within the general society across the country in September 2019, was a clarion call to stop the abuse of girl-children and women. By perpetuating the predominant perspectives of women as incapable and incompetent within leadership through a continued patriarchal system, the absence of women as role models (Moodly and Toni 2015a), continue to perpetuate the narrative that girl-children cannot aspire to roles of leadership and be role-models in this regard.

\section{THE CONTEXT OF LEADERSHIP FOR WOMEN IN HIGHER EDUCATION: IDENTIFYING AND NEGOTIATING CHALLENGES}

The following section reflects on the cultural and structural challenges identified both in the literature, as well as in qualitative research by Moodly and Toni (Moodly 2015; Moodly and Toni $2015 \mathrm{a} ; 2015 \mathrm{~b} ; 2017 \mathrm{a} ; 2017 \mathrm{~b} ; 2017 \mathrm{c} ; 2019)$, as challenges to women on a trajectory to leadership in higher education.

\section{Gendered cultures}

Consistently, literature reflects structural and cultural aspects of the higher education milieu as 
negatively experienced by women in both academia and towards a pathway of leadership. Interestingly, Gallagher and Morison $(2019,1)$ point out that "historically" "all institutions were developed by, and for, men". They further state that it is only in the "mid- $20^{\text {th }}$ century" that women's access to universities was facilitated by "societal change". Women's "journeys" to leadership are "very different" to, and mostly later than those of "many male counterparts" (Gallagher and Morison 2019,1) and is attributed to various factors, including the traditional expectation of prioritising family responsibilities (Gallagher and Morison 2019; Shinbrot et al. 2019). As such, women do not necessarily reach the same milestones as men at the same chronological age.

Gallagher and Morison (2019,4), argue that "embedded in organisational culture are perceptions of leadership behaviours" mostly associated "with masculine behaviours". A further challenge is that the behaviour traits found to be "attractive in men", are viewed "negatively" when displayed by women. The "negative consequences" for women ("and men") who "act outside of expected gender norms" is also highlighted by Shinbrot et al. $(2019,122)$. They further cite Heilman, Wallen, Fuchs and Tamkins (2004), who state that "women are often less well-liked and more belittled" when seen as "successful leaders" particularly in "maledominated fields". It is further reflected that, though this may not be generalised, women bring a more servant-leadership form which has as yet not been fully embraced as an effective style of leadership at senior levels. This form of leadership is influenced by the traditional societal roles expected of women, including the role of "child-bearing and caregiving to their own families (and), extended families" and often extends into the workplace (Toni and Moodly 2019, 186). It is further characterised by a "caring and service-oriented style", being "sensitive" and using "gentle persuasion" (Moodly and Toni 2017b, 163). In contrast, Kolb (1999) as cited by Shinbrot et al. $(2019,122)$, states that there is "evidence" that "perceptions have shifted towards androgynous leadership styles, where there is a balance of both masculine and feminine characteristics". Despite this, Shinbrot et al. (2019, 122 and 129) conclude that "rising to leadership positions remains difficult for women and most organizations remain fundamentally gendered" and androgynous leadership has as yet not been completely embraced". Their research findings further reflect that women continue to experience societal patriarchal structures of "masculine values, power and dominance".

\section{The old boys network/club}

According to Acker (2006 cited in Shinbrot et al. 2019, 122), one of the reasons for men's success in rising to leadership in organisations, is that "networking" in these spaces "favors men". The authors further cite Morgan and Martin (2006), who observe that "powerful 
networks tend to be occupied by men, ...; where trust and rapport are built through traditionally male activities like golfing or hunting". The authors also indicate that "research shows that people tend to hire employees that are similar to them, a phenomenon known as homosocial reproduction". They further state that the "hiring process" is "often commanded by ... men" and as such perpetuates the gendered cultures of organisations, influencing the degree to which women are included in and acknowledged for leadership (Shinbrot et al. 2019, 122-123). Surawicz (2016) linked this to the glass-ceiling phenomenon in which women experience "bias" directly related to a male-dominated institutional culture.

\section{Family responsibilities and work-life balance}

Family life, despite changing societal attitudes in this regard, is still viewed as the primary domain of women as care-givers (to children and within the family) (Gallagher and Morison 2019; Shinbrot et al. 2019). Gallagher and Morison $(2019,4)$ indicate that "research suggests that women are often attracted" to professions that facilitate the balancing of work and family life. As women are still expected to play the predominant nurturing role in family life, it is observed that a career that leads itself to balance in this regard, is often more attractive to women. One such career is dentistry, which offers reasonable working hours, no on-call responsibilities, and flexible hours, amongst other attractive attributes, thereby contributing to a professional and family life balance. Gallagher and Morison $(2019,3)$ observe that though the profession of dentistry in itself is considered attractive to women, this may not necessarily be the case in dentistry in "academia" and the accompanying "challenge of professional leadership". The work-life balance appears more challenging for women in roles of leadership than in professional careers. This may be due to the expectations of prioritising family responsibilities over one's leadership aspirations. Shinbrot et al. $(2019,123)$, cite Cheung and Halpern (2010) who state that "women who have no children are more likely to achieve leadership positions". Shinbrot et al. $(2019,124)$ conclude that women's access to resources including finances and to influential decision-making, continued to be limited due to the "gender norms" expecting that women prioritise family and childrearing in a "work-life family balance". Surawicz $(2016,1434)$ argues that the "biological clock" is "often out of sync with the academic clock" which creates "tension between academic activity and other aspects of life".

\section{Need to establish allies, support structures and mentoring}

Shinbrot et al. $(2019,124)$ observe that men play a critical and pivotal role as "integral allies, partners and resources" in affecting "gender change". The authors discern the importance of 
identifying and understanding "who tends to become a male ally". They purport on the basis of studies, that "men who are motivated by social responsibility and the desire to help others ... are more likely to become allies of women". Being able to identify challenges such as "sexism" against women though, and acting upon and "confronting" these, are not necessarily "a foregone conclusion" as various factors can impact on the decision to take such action. These, according to Shinbrot et al. (2019), can include the risk and cost associated with speaking out, the negative "branding" or perception as a "trouble -maker". The authors further argue that "men have their own power relations, which disrupt their perceived ability to make a difference". Acting outside of perceived "gender norms" may also impact on "mental distress" (Sandfort, Melendez and Diaz 2007, as cited by Shinbrot et al. 2019, 124). Shinbrot et al. (2019) conclude that there is a need for men and women to "make strategic alliances" towards supporting a balance in leadership towards sustainable development, but that the ability to facilitate such could be more challenging in the "South" (inclusive of South Africa) as opposed to the "Global North" where "hegemonic masculinities are shifting more rapidly".

Surawicz $(2016,1433)$ refers to the lack of women achieving senior and executive leadership positions, despite attaining academically, as "the leaky pipeline". She maintains that the "glass-ceiling" phenomenon is still a reality as women are pressured by "leaky pipeline" issues including "work-life integration and the need for leadership development". Surawicz (2016) further proposes several forms of support for women, including the provision of "adequate mentoring and leadership training" which could help both women and men. Support efforts within institutions should be both "top-down and bottom-up" according to Surawicz (2016, 1435), inclusive of "financial and administrative support". In her view "professional societies" within fields of expertise should also form part of support and networking structures, that amongst others, "sponsor programs that promote opportunities for women ... and facilitate networking". Surawicz $(2016,1436)$ also advises that a system of multiple mentors may assist as both family and professional support systems, and that a peer support system should be included in such a structure. Role models and leadership development form part of this structure.

\section{Lack of implementation of policies, legislation and practices}

Policies promoting access and equity to women have been prevalent, in areas of South African society. These include, amongst others, the Education White Paper 3 (Republic of South Africa 1996); the National Plan for Higher Education (Department of Education 2001) and the Women Empowerment; the Gender Equality Bill (Republic of South Africa 2013). Policy in itself does not translate into equitable practices as researchers continue to study inequities and imbalances 
in relation to women within societies globally. Surawicz (2016, 1434 and 1436) argues that "academic policies" should be "fair" and regularly reviewed to consider the family-work life balance as experienced by women. She suggests that "flexible work policies and part-time work" could alleviate the work-family life tension that women often experience (Surawicz 2016, 1434 and 1436).

\section{THE ROLE OF MEN IN ACHIEVING GENDER EQUALITY AND JUSTICE}

Hendra, Fitzgerald and Seymour (2013) recognise that men and boys hold power disproportionately within society, arguing that this power should be used in a transformative agenda. Men in positions of power should direct this towards challenging and influencing the structural imbalances and inequality in power relations within society. Men are called upon to use their positions to stimulate "rethinking and transforming gender stereotypes and traditional norms of masculinity and femininity" (Hendra et al. 2013, 112). In highlighting the critical role of men and boys in fighting for gender equality, the authors cite the Beijing Declaration and Platform for Action (1995) which "encouraged men and boys to fully participate in actions to support gender equality, and emphasized the principle of shared power and responsibility between women and men at home, in the workplace, and in the wider national and international communities". They further indicate that numerous men's organisations and networks were formed "as agents towards gender equality" $(2013,112)$, at the same time lamenting that "men and boys remain a largely untapped resource for the pursuit of gender equality" $(2013,112)$. Contextualising and arguing that this falls on men and boys as part of a broader community, Hendra et al. (2013) purport that the former has a duty and responsibility in actively transforming society in relation to equal rights of women and girls. It is because of these gender inequalities, that there is violence against women and girls which is perpetuated in their view, by the imbalance in power relations. "Freedom from violence is the right that underpins all other rights. Violence, or the threat of violence, is the primary means through which power is exerted over others. It facilitates and perpetuates discrimination, in addition to being a manifestation of discrimination" (Hendra et al. 2013, 112).

Fronteddu (2013) states that whereas in the past, matters pertaining to women's equality were perceived as issues as addressed by women, there has been a changing view that all have responsibility in this regard. The inextricable role of men and boys in matters of inequality has increasingly been recognised and Fronteddu (2013) cites various commissions and campaigns which have affirmed men and boys as co-responsible with women for the promotion of gender equality. Some of the commissions and campaigns highlighted by Fronteddu (2013) include, the 2004 United Nations Commission on the Status of Women (CSW), the 2006 Council of the 
European Union which adopted conclusions on men and gender equality, and the European Commission's Strategy for equality between women and men 2010-2015.

\section{PROBLEM STATEMENT}

The scarcity of women in leadership and as role models perpetuate the narrative of women as unable to lead and to be role-models towards which girl-children and women can aspire. Shinbrot et al.'s $(2019,120)$ research reflect that women are in fact the major contributors to "sustainable development" being "stewards of natural resources" and affirm the role of women as leaders and key role-players in societal survival. As previously indicated, and as assumed as common-sense, given the socio-economic context of our society, women should be occupying spaces within senior/executive leadership at the very least, in equal proportion to men. This, given the increased proportionality of women in society and the multiplicity of implications for, amongst others, the socio-economic viability and sustainability of the country. Not only is it an injustice to women, but the economic ramifications in continuing the disproportionate status quo reflected in the continued lack of development and capacitation of women as part of the leadership of higher education and the workforce within various economic sectors, has been reiterated in research as of dire consequence to sustainability and the survival of societies (Shinbrot et al. 2019). Consistently argued by Moodly (2015) and Moodly and Toni (2015a; $2015 \mathrm{~b} ; 2017 \mathrm{a}$ ), is that women in leadership are needed as role models to inspire girl-children and women within societies which continue their oppression. How much more powerful a message when women who facilitate liberation of girl-children and women, occupy the spaces of leadership within the domain of higher education (a tool of liberation) and who serve as role models. The challenge is to continually contest and break down structural barriers within higher education that inhibit women towards leadership, and to develop structures that support a trajectory towards women's leadership. Men in leadership play a pivotal role as persons of influence and authority in this regard (as reflected in literature such as Shinbrot et al. 2019). The focus of this article is to gain insight into perspectives of men in senior/executive leadership on structural barriers that women face within higher education institutions as outlined in the literature, given the dearth of literature on male perspectives. The aim is to ascertain if there is congruence between women's lived experiences and men's perceptions of these structures so as to identify pathways that may contribute towards redressing the inequities within senior/executive leadership.

\section{METHODOLOGY}

A qualitative approach was followed focused within the interpretative paradigm (Cresswell 
2012), with interviews with six men in university leadership. The initial targeted groups were vice-chancellors (all men at the time of the research) and deputy vice-chancellors at four universities in the Eastern Cape Province of South Africa. Deans and campus rectors were also identified. The open-ended engagement allowed flexibility for further probing (Okeke and Van Wyk 2015), with content and thematic analysis bringing to the fore not only areas as reflected in literature, but also areas that had not been highlighted or foregrounded, or even mentioned by women in the author's previous research.

\section{PROFILES OF THE SAMPLE GROUP}

In line with confidentiality and protecting the anonymity of interviewees, it is only revealed that the men were within the age ranges of 40-60+, and mostly black African. All occupied senior/executive positions within the Eastern Cape-based universities.

\section{LIMITATIONS}

The research was limited to four universities and six men in leadership. Findings thus cannot be generalised. Gender identification and race in their complexities, and the impact on leadership were not explored. The author acknowledges the various complexities around the identification of binaries and non-binaries in terms of gender, as well as the discourses in this regard. The experiences of women along racial classifications as reflected in literature, is also acknowledged though not explored.

\section{ENGAGING WITH THE FINDINGS}

When reflecting on responses, participants are referred to as A, B, C, D, E and F as a form of anonymity in line with research ethics.

\section{Gendered spaces and the old boys network/club}

The responses reflected that the old boys' club/network was still prevalent within institutions, and although it had morphed from its original form, it was mostly a male form of networking (as opposed to female). One participant understood it to be an "incoko" (informal/social gathering space where caucusing took place) where men got together around "braais" (barbeques) and discussed matters pertaining to the formal workplace. He was also of the view that these informal structures thrived more on campuses with smaller settings, where it was easier for persons within a limited geographical space to influence decisions within the institution. To him, this was not something prevalent on the campus where he was part of the leadership. Though arguing in his context, that geographical space and proximity of persons in 
this space determined the existence and influence of informal structures such as the old boys' network, the engagements with most of the respondents confirmed that such informal structures were both still in existence and prevalent outside and within institutions.

For Participant B there were "definitely gendered male centred networks in the institution". He stated that power "did not just happen" but was "reproduced" in a "buddybuddy set of relations". Though it was often "racialised" it also ran across "linguistic lines" and was "cross-cultural". It was a "patriarchal space" with "almost a kind of conspiracy ... or a convergent ... across the racial boundaries when it comes to male(s)". "Maleness in an institution and male cultures often thrive on the notion of power that emphasises force ... and domination ... or positional power of authority". He stated that caution should be exercised not to "stereotype" as "not all males function" in this manner. Each institution may differ in its "notion of gender" but historically in his institution, it was a culture that "asserted law and order authority" with a "regimented system of control". This was also used as a way to "silence people in the organisation".

Participant C's view was that there was a "correlation between institutional culture" and male-centred networks, evident in some faculties where they were "stubbornly unable ... or ... even unwilling to accelerate pathways for women's advancement" in their fields. "When you look at the spread of gender distribution in those faculties then it will be quite clear that something is wrong". On a question as to how the university navigated these spaces, participant C stated that the "biggest problem was transformation". Though there were "shifts at the top" as all the Deans were "black", he would have wanted to see more "demographic diversity". The institution still had "a long, long way to go" in terms of transformation and he was "not so confident" that they were "near successful in disrupting those networks". This would need a change in institutional culture. Disruption, if it happened was "politically" and at the time when “issues are brought to ... attention". Thus, "the ability to shift the system around not just in numbers but (also) in cultural changes" associated with the disruptions had not been as successful. He indicated that institutional culture could not be extricated in this pattern as it was this that "reproduces the inequalities". He stated that "unless you break down the sources of ... inequality ... you are not going to tackle the problem ... because human beings will still continue to do exactly the same as they have done".

Participant C indicated that not only did the "old boys' network ... exist" but part of this was "young boys' (network)". The younger men were "co-opted to those kinds of ... informal structures" and as such the "outcomes" that were favoured would be attained, through also incorporating the younger men, who "served under them". These forms of clubs were "not declared", nor did they have "constitutions" and normally operated "outside of the formal 
structures", such as at "social gatherings" like the "golf course". Though participant D was not certain if the "old boys" network existed within his institution, he was of the view that there was "a time ... a formal ... and informal university" with the latter "calling the shots". What happened in the "formal" had been "concluded in the informal" and though he had no "empirical evidence" he was of the opinion that a structure "outside (of) the formal structure" drove the institution. He was of the view, that given the "patriarchal nature of society", that such a structure was predominantly male (though he could not say if women were part of such a structure).

Participant F indicated that he imagined that it existed, "even in a tearoom conversation which may be exclusionary ... social spaces". He mentioned, as examples, conversations of "cricket and you know nothing about cricket ... so you feel excluded". His views reflected those of participant A that geographically smaller spaces were fertile grounds for such structures. It was in these structures "outside of the formal meeting structures" where issues were discussed. He was also of the view that it was "more likely men than women" in these social spaces, and that in "certain departments there was not a single woman" and that it would take "a significant culture change if there were to be a woman academic in those departments". The more homogenous the structure, the more challenging it was for someone perceived as an outsider to penetrate such a space, and "these kinds of networks served as useful support structures for those within them. Not only did it enable exchange of views, but it was a space to ask each other questions and advice" and so these networks were "quite strong". The power and influence of such structures were quite obvious in the formal settings of university meetings, as you could "tell when certain individuals have a discussion on an issue ... they are not ... engaging for the first time on those ... they do exchange views on issues outside of the formal structures".

The views expressed mostly reflect consensus that the old boys' club/network is a reality within institutions, and though it may have morphed somewhat, it is perceived as still predominantly male, and exists amongst those with power and influence. It is within these informal and social spaces that informal decisions are taken and formalised within the institutional structures. It still facilitates positional power and thus the dominant gendered discourse which favours a masculine institutional culture. Breaking down and challenging such networks, is part of the challenge of transforming the institutional culture. The responses reflect that though the participants were mostly aware of such formations, they did not necessarily challenge such, or reflect on these. The deeper layers of such formations and their bolstering of the status quo had not been engaged. Reflecting on the responses in relation to Bhaskar's and Archer's theories of critical and social realism respectively, though there appears to be a conscious awareness of these formations, the grappling with such and the deeper impact of such 
on institutional culture in relation to women had not been engaged. Recognising such formations as perpetuating gender inequalities, especially in relation to women and challenging the status quo towards social justice is not apparent in the responses of most participants. A deeper understanding of the extent of the impact of such formations on women's experiences was also not immediately evident, though it is acknowledged that there was only one session of engagement with each participant.

\section{Structures that promote women's trajectory to leadership}

Whereas most participants indicated that there were no formal structures that supported women on a trajectory to leadership, two pointed to formal programmes aimed at developing women in academia in their respective institutions. These strengthened opportunities towards academic progress, and it could be argued that these were also enablers towards academic leadership. Participant A's responses reflected challenges in attracting qualified and competent persons, not only women, to the university, as well as into leadership positions. It was for this reason that the institution did not necessarily focus on the recruitment of women into executive leadership. Though there was acknowledgment for the need to recruit women, the over-arching justification for lack of focusing on equity in terms of gender, was the shortage of interest in these positions by experienced, suitably qualified persons in general. Aside from the challenge to attract women, there were also no structures that facilitated the preparation of women within the university towards such positions. This rationale appeared more of a justification for the retention of the status quo, an acceptance that an argument of geographical location and accompanying resource shortages would be sufficient grounds for understanding the lack of agency. It also appeared to be the justification for an absence of an internal focus to develop structures that support women on such a trajectory. In this regard it is argued, there was no exercise of agency to influence the status quo both externally and from within, but that a complacency has set in, with the unuttered narrative that the institution's situation should be understood. It is this complacency that needs to be shaken, as the argument could echo across the sector, each leader justifying their institution's position and the lack of exercising their agency. Most participants stated that there were structures within the academic and research spheres that focused on the promotion of women, but at a "system-wide level", and in "institutional leadership", and in "administration", such structures were absent. This acknowledgement reflects that conceptualisation around the trajectory of women and support structures in terms of this, has not clearly been visualised. The focus and emphasis within institutions have not been to the extent of challenging the lack of structures supporting women, rather than an attempt at justifying the lack of such focus. The danger in allowing this narrative 
to dominate this space, is what contributes to apathy, a resignation to the challenges, rather than an opportunity for looking at different pathways to follow. In terms of Bhaskar's theory of differentiated levels of reality, at an empirical, observed level, there is a lack of structures supporting women which can be ascribed to challenges as experienced within these institutions. However, the question can be asked as to whether there are not deeper actual and real levels where structures and mechanisms exist as barriers to supporting women towards leadership? And that it may be these underlying structures and mechanisms that have resulted in the absence of such support systems? Archer's theory argues that not only should there be the recognition of such underlying mechanisms and structures, but the exercising of agency in disrupting such is needed. There appears to be a deeper reality of morphostatis, and a lack of movement towards addressing social justice, reflected within the empirical, observed level of a lack of systems and support structures for the promotion of women. Unless we agitate for an awakening from this sense of justification of lack of agency, towards a recognition of and agency towards disrupting the deeper structures and mechanisms, women will continue to be in the minority within positions of leadership. The focus has to be on agency towards an enabling environment and the agitation for structures in this regard.

\section{Policies and plans}

Participant A was not certain that there were institutional policies and plans that encouraged the employment and development of women. He referred to national imperatives and the Department of Labour's equity imperatives that the institution generally was aware of, but pointed to the general challenge of attracting staff as a challenge to focus on equity targets. Participant B indicated that the institution had not necessarily taken into consideration "the social and other responsibilities" of women. Using a "household context" as an example, he indicated that this was not taken "into account", in possibly adapting academic and administrative support towards women and career-pathing. He stated that in considering support for women in terms of policies and plans, there was also a need to consider the "reconstruction of social relations, given the multiple forms of relations women (and men) formed". The "traditional patriarchal assumptions about women's social responsibilities" had to be reconstructed and he questioned the extent to which the university's "policies and strategies" created "more flexible environments for shared responsibilities" "between couples ... having to share responsibilities of child-rearing and other kinds". He indicated that policy at his institution did not necessarily consider the deconstruction of the traditional "family concept" and thus there were "normative assumptions" that were "built" into policies "based on very traditional notions of male-dominated households". He was of the opinion that the policy 
structure at the institution was fundamentally flawed in this regard and women at the institution had "also agitated" against this over a period of time. There had, however, not been "an alternative conception of what families could be" and policy in this regard, had not been addressed.

Participant E indicated that though policies and plans were in place, these were not necessarily particular to women. Instead, these policies covered "a whole range of people who had (previously) been excluded, inclusive of women". He pointed to women leaders who guided the trajectory of the institution in their roles on Council and in the Chancellorate, even though they were not directly involved in the operational structures. Their influence in their oversight capacity impacted on the trajectory of the university in terms of policy and practice. This reiterates the researcher's argument that women need women as role models and as agents of transformation in higher education leadership. Participant E, acknowledges that the impetus for addressing a change in policy and practice was the representation of women on Council and within the Chancellorate exercising their agency and advocating for women in leadership. $\mathrm{He}$ also indicated that five directorates under his supervision were headed by women, and together with them he ensured that policies moved in the direction of capacitating and supporting women. The increased number of women in senior administrative positions, ensured that support for women was addressed in terms of formal structures.

Participants generally agreed on the need for policies and plans to promote women in terms of opportunities for them to develop and play a greater role in leadership. Participant B also stated that programmes should consider the non-linear and non-chronological life cycle continuum that women follow in terms of career pathing (the many commitments women have and the interrupted nature of their journey with family and other commitments). Participant $\mathrm{F}$ indicated that there was a need to "invest" in the promotion of women into leadership positions and that councils of universities had to be encouraged "to give priority and preference to women in filling positions of deputy vice-chancellor and vice-chancellor". He was supportive of a "mechanism of identifying (women) academics at faculty dean level, who (could) be supported and be given opportunities for self-development" so as to successfully compete for positions at the upper echelons of university leadership. His view was that "we cannot leave this thing to chance - we can't simply say that there are natural processes that will in the fullness of time help us to correct the glaring imbalance in the gender composition of the senior leadership of universities". However, it was a challenge that "required leadership ... at a vice-chancellor level" as the "normal processes that have always been followed" were likely to yield the "same profile of people that this process has delivered in the past". "Somehow, we need to disrupt these normal processes and find ways of ensuring that we bring women on board, not only 
because they are women - because they are just as good ...”. This advocacy for disruption of the status quo, is what is needed in the agency of men in leadership. Understanding the need for disruption of the status quo must be married to exercising agency in this regard. The deeper reality of the structures and mechanisms that maintain the status quo of social injustice has to be disrupted through those in leadership. Men who are in positions of power, need to recognise and disrupt the deeper structures and mechanisms at play. It may be that the challenges as manifested in the surface realities may diverge attention in this regard. The disproportionate power relations which perpetuate social injustice towards women and girl-children can only be disrupted through a recognition of the deeper realities and a conscious engagement in transforming such.

\section{Mentoring and support structures for women}

Respondent A stated that the university leadership recognised the need to develop the "next generation of leadership" though it was not necessarily "specific to women". The academic organogram was under review so as "to grow the next generation of leaders" and "grooming" was identified as a strategy, and as the discourse unfolded the issue of gender equity in leadership may become a focus point. Only one of the deans at the institution was female at the time, and represented less than ten percent of leadership at deanship. The question one could ask is, how does one support and develop women to executive leadership level, if there is still a deficit trajectory?

Respondent B indicated that mentoring at his institution was "unstructured" and "informal" but that he did "not know everything in the institution". Mentoring was "fragmentally promoted" and there was at the time thought of setting up a more concrete structure in this regard. He was of the view that the fragmented approach could not and did not "tackle the systemic challenge" and that there was a need for a "structure" that induced "an environment for the support of women at a much more systemic level". Respondent C indicated that there were no formal structures for mentoring women but that there was funding available as a mechanism to support mentoring, amongst other forms of support. He mentioned the nGap programme, a new Generation of Academic Programme supported by government, as a form of support, though acknowledged that this was not necessarily specific to women. He also stated that the "grant" (referring to the teaching and learning support funding) from the Department of Higher Education and Training also allowed for the support of women as part of the broader support of academics in their development. The challenge was that it was assumed that "the playing fields are level", which was not the case. Equal forms of support were given to both men and women because of this assumption. The responses of the three participants as 
mentioned, generally reflected that mentoring was not formally planned, nor structured and was not a focus as part of a planned strategy. Again, as previously stated, the deeper realities of the structures and mechanisms that maintain the status quo need to be recognised and challenged. The empirical reality is that it would appear that there is an assumption that women do not need any additional forms of mentoring and support structures. The realities of the challenges that are unique to women and girl-children have not been recognised and seemingly are not understood, hence the lack of differentiated support to women.

\section{CONCLUSION}

As in Shinbrot et al. (2019), this research concludes that women's (as previously interviewed) and men's responses on views towards women and leadership do not necessarily differ. Men were just as likely to agree that women have a "unique lived experience" and experienced a "male-dominated" institutional and family/societal culture (Shinbrot et al. 2019, 128). As further observed by Shinbrot et al., participants in the research had willingly participated (as in this project) and they may possess a level of "inherent" sympathy towards women. However, their responses may not necessarily be reflective of all men in leadership. Despite the understanding of women's challenges within the gendered spaces by the men as interviewed, there is a lack of appreciation of and engagement with the deeper realities of women's experiences of the mechanisms and structures of morphostatis, as explicated by Bhaskar and Archer. Though there is recognition of the empirical realities (as manifested in the old boys' club, the lack of mentoring and support structure, etcetera), the author argues that there may not be an appreciation of the depth of the actual and real underlying levels which maintain the status quo. Neither is there agency in engaging with these levels. The surface (empirical) reality thus dominates and clouds the deeper layers of reality. Thus, the challenge of geographical location, for example, was the argument of the majority of the respondents, as a reason for not being able to attract experienced academics of a competent research calibre, including black academics, let alone women in particular. Meaningful engagement with issues of social justice (and gender equality) and conceptualizing the differentiated levels of reality towards morphogenesis is clouded by the more immediate day-to-day challenges. Men (and women) in leadership need to step back and reflect on their role and responsibilities in addressing gender inequalities and the disproportionate power relations within our societies. Men in leadership, in particular need to recognise their roles in engaging with the inequalities within our societies, and their agency in disrupting such inequalities. In the absence of a morphogenetic approach in analyzing and interpreting the deeper layers which perpetuate and maintain social injustices in our societies, which amongst others, form barriers to women towards leadership, men would not be taking up 
their co-responsibilities in addressing gender inequality. It cannot be accepted that because of a general challenge in attracting black and senior academics to our institutions, this outweighs prioritising addressing the marginalisation of women. Part of the discourse should be to consider all of these challenges and not prioritise one over the other. It is this justification that puts us in the perilous condition of perpetuating the status quo. There has to be agitation towards challenging this perception. The reconstruction of social relations as indicated by participant B, speaks to the need for discourse around policy and the structure of policy and advocacy that influences what may still be deep underlying levels of normative assumptions on which policies are constructed. Leaders need to do more in exercising their agency as persons in positions of influence, in disrupting traditionally accepted processes. Leadership needs to agitate to explore ways of ensuring women are represented at the highest levels of leadership, through stimulating re-thinking around policy-planning and implementation, and the underlying notions that influence such.

Broader still, within the frameworks of critical realism and social realism, it is argued that there is a form of morphostasis in the lack of agency and the preserve therefore of what is described by Bhaskar, as the "real" layer of deep structural and cultural constructs that underpin the higher education milieu. Though there is acknowledgement and a sense of support for women on a trajectory of leadership, the form thereof is not of a conscious, decisive and concerted nature (a form of morphogenesis). Conscious awareness of their positions of influence and power in advocating for women towards leadership was not reflected in the discussions. The participants supported and understood equity principles and that women needed to be in the foreground of transformation of leadership. What was not apparent, was consciousness and their exercise of agency or that there was urgency in addressing the status quo. The challenge is that the complexity of the HE milieu is such that the prioritising of advocacy for women in leadership is lost in a myriad of challenges. The issues of finding academics, particularly black academics to occupy positions and as one participant indicated "a warm body in front of a lecture - that" (own emphasis) is the priority. Thus, the voices of the struggle and complexities of women in this milieu become but one of the many challenges. And that cannot be! In as much as we experience the challenges, there are (own emphasis) areas that can be addressed; such as the old boys' network and the subtle forms of it, review of policy underpinnings, and implementation of focused support structures and programmes for women in particular. Persons in leadership, both men and women, need to be held accountable for this. And those in leadership need to drive this. And here, the findings speak to all as part of our public higher education system.

Men in leadership should exercise their agency more conscientiously towards challenging 
institutional cultures that continue to inhibit the advancement of women towards leadership. Exercising agency, as purported by Archer and also argued by Monnapula-Mapesela (2017), moves our milieu from a state of morphostatis to that of morphogenesis. There is a danger in complacency in the acceptance of continuous challenges as justification for the lack of exercising agency more assertively. Failure to act may also reflect as failure in the redress of the marginalisation of the girl-child and women in our society, and failure in promoting social justice from a position of influence and power.

\section{REFERENCES}

Archer, M. 1995. Realist social theory: The morphogenetic approach. Cambridge: Cambridge University Press.

Archer, M. S. 2000. “Morphogenesis - Realism's explanatory framework." In Being human, 59-94. Cambridge: CUP.

Ballenger, J. and S. F. Austin. 2007. "Women's access to higher education leadership: Cultural and structural barriers." Forum on public policy, 1-20.

Bhaskar, R. 1989. Reclaiming reality: A critical introduction to contemporary philosophy. London: Verso.

Boughey, C. and S. McKenna. 2017. "Analysing an audit cycle: A critical realist account." Studies in Higher Education 42(6): 963-975.

Bonorchis, R. 2019. "South African protests spread to Cape Town over murders of women." Daily Maverick 5 September 2019. www.dailymaverick.co.za (Accessed 5 September 2019).

Carolus, A. 2019. \#AmInext: Surviving South Africa and its femicide epidemic. https://www.alltheprettybirds.com (Accessed 6 September 2019).

Council on Higher Education. 2019. Vital Stats Public Higher Education 2017. Council on Higher Education. Pretoria

Cresswell, J. W. 2012. Educational research: Planning, conducting and evaluating quantitative and qualitative research. $4^{\text {th }}$ Edition. Boston: Pearson.

Chipkin, I. and S. Meny-Gilbert. 2013. Understanding the social justice sector in South Africa: A report to the RAITH Foundation and Atlantic Philanthropies. Public Affairs Research Institute. South Africa.

Department of Education. 2001. National Plan for Higher Education. Ministry of Education. Pretoria: Government Printers.

Fronteddu, C. 2013. "The Role of Men in Gender Equality." https://timeforequality.org/news/the-roleof-men-in-gender-equality/ (Accessed 14 July 2020).

Gallagher, J. E. and S. Morison. 2019. "Women in academic leadership: A chance to shape the future." Journal of Dentistry (87): 1-5.

Hendra, J., I. FitzGerald, and D. Seymour. 2013. "Towards a new transformative development agenda: The role of men and boys in achieving gender equality." Journal of International Affairs Fall/Winter 67(1): 105-122.

Monnapula-Mapesela, M. 2017. "Developing as an academic leader in a university of technology in South Africa: Dealing with enabling and constraining teaching and learning environments." Critical Studies in Teaching and Learning 5(2): 69-85.

Moodly, A. 2015. "Gender equity in South African higher education leadership: Where are we twenty years after democracy?” Journal of Social Sciences 42(3): 229-238. 
Moodly, A. and N. Toni. 2015a. Women's access towards higher education leadership: Where are the role models? Journal of Social Sciences 45(1): 45-52.

Moodly, A. and N. Toni. 2015b. "Women's voices of and on leadership in higher education." https://doi.org/10.20853/31-3-917. Paper presented at the Global Research and International Services (GRDS) 7th International Conference on Teaching, Education and Learning (ICTEL), 10-11 October 2015. Pointe aux Piments, Mauritius.

Moodly A. and N. Toni. 2017a. "Accessing higher education leadership: Towards a framework for women's professional development." South African Journal of Higher Education 31(3): 138-153.

Moodly A. and N. Toni. 2017b. "Re-imagining higher education leadership - in conversation with South African female deputy vice-chancellors." Perspectives in Education 35(2): 155-167.

Moodly A. and N. Toni. 2017c. "Women's voices of and on leadership in higher education: A South African context. Journal of Educational Sciences 16(1): 184-198.

Moodly A. and N. Toni. 2019. "Intrinsic and extrinsic factors in empowerment of women towards leadership - a study in higher education (South Africa)." International Conference on Gender Research (ICGR19). E-Book ISBN 978-1-912764-16-7. E-Book ISSN - 2516-2810; Print version ISBN - 978-1-912764-15-0; Print version ISSN: 2516-2802: 407- 416.

Neier, A. 2015. "Human rights and social justice: Separate causes." In Can human rights bring social justice?, ed. D. Lettinga and L. van Troost. Amnesty International, Netherlands.

Nkanjeni, U. 2019a. "Wrap|A; The details on SA's femicide protests and shutdowns." In News/South Africa Times Live. www.Eslive.co.za.cdn.ampproject.org. (Accessed 5 September 2019).

Nkanjeni, U. 2019b. "CrimeStats revisited: Murder, rape and violent crime - these are the numbers." In News/South Africa Times Live. www.timeslive.co.za. (Accessed 10 September 2019).

Okeke, C. and M. van Wyk. (Ed.). 2015. Educational research: An African approach. Cape Town: Oxford University Press.

Rawls, J. 1971. A theory of justice. Harvard University Press.

Republic of South Africa. 1996. White Paper No.3 on Higher Education Transformation: Pretoria: Government Printers.

Republic of South Africa. 2013. Women Empowerment and Gender Equality Bill. National Assembly, Pretoria: South Africa.

Shinbrot, X. A, K. Wilkins, U. Gretzel, and G. Bowser. 2019. Unlocking women's sustainability leadership potential: Perceptions of contributions and challenges for women in sustainable development. World Development (119):120-132.

Surawicz, M. 2016. Women in leadership: Why so few and what to do about it. Journal of the American College of Radiology, 1433-1437.

Toni, N. and A. Moodly. 2019. "Do institutional cultures serve as impediments for women's advancement towards leadership in South African higher education?" South African Journal of Higher Education 33(3): 176-191. http://dx.doi.org/10.20853/33-3-3137. (eISSN 1753-5913.). 